\title{
Herpes zoster in patients with sciatica
}

\author{
Der-Shin Ke' ${ }^{1}$ Chao-Yu Hsu ${ }^{1,2,3,4,5,6,7}$, Cheng-Li Lin ${ }^{8,9}$, Chung-Y. Hsu ${ }^{10}$ and Chia-Hung Kao ${ }^{10,11,12,13^{*}}$
}

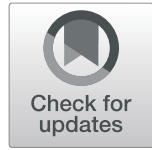

\begin{abstract}
Background: Several diseases are associated with herpes zoster $(\mathrm{HZ})$. However, whether sciatica is a stressor leading to $\mathrm{HZ}$ development remains unclear. Here, we evaluated the occurrence of $\mathrm{HZ}$ in patients with sciatica.

Methods: The sciatica cohort consisted of patients first diagnosed as having sciatica between 2000 and 2012. All patients with sciatica were randomly age, sex and index year matched with control individuals without sciatica. The primary outcome was diagnosis of $\mathrm{HZ}$. All individuals were followed until $\mathrm{HZ}$ diagnosis, withdrawal from the insurance, death, or December 31, 2013, whichever occurred first. HZ risk in the two cohorts was further analyzed with age, sex and comorbidity stratification.

Results: In total, 49,023 patients with sciatica and 49,023 matched controls were included. Female patients were more likely to have $\mathrm{HZ}$ development than were male patients [adjusted hazard ratio $(H R)=1.07,95 \%$ confidence interval $(\mathrm{Cl})=1.02-1.12]$. After adjustments for all the covariates, $\mathrm{HZ}$ risk was significantly higher in the sciatica cohort than in the control cohort (adjusted $\mathrm{HR}=1.19 ; 95 \% \mathrm{Cl}=1.12-1.25$ ).
\end{abstract}

Conclusion: Sciatica increased HZ risk. Thus, HZ risk should be addressed whenever physicians encounter patients with sciatica, HZ vaccination should be considered especially those aged over 50.

Keywords: Sciatica, Herpes zoster, Depression, Obesity

\section{Background}

Sciatica is characterized by a burning sensation or shooting pain caused by irritation or compression of the sciatic nerve, and the most common cause of sciatica is spinal disc herniation. Sciatica prevalence and incidence rates have been reported to be $1.2-43 \%$ and $1-37 \%$, respectively; the large variations may be due to the differences in definitions or study population in the concerned studies $[1,2]$. Sciatica treatment intensity is dependent on disease severity, and the treatment can include exercise, manual therapy, medication, spinal injection and surgery [3].

Herpes zoster (HZ), a painful vesicular eruption, occurs due to varicella-zoster virus (VZV) reactivation.

\footnotetext{
*Correspondence: d10040@mail.cmuh.org.tw; dr.kaochiahung@gmail.com

${ }^{10}$ Graduate Institute of Biomedical Sciences and School of Medicine, College of Medicine, China Medical University, No. 2, Yuh-Der Road, Taichung 404, Taiwan

${ }^{11}$ Department of Nuclear Medicine and PET Center, China Medical University Hospital, Taichung, Taiwan

Full list of author information is available at the end of the article
}

HZ incidence was 9.92 per 1000 person-years in immunocompetent, unvaccinated adults aged $\geq 50$ years, with a case-fatality rate of $0.04 \%$ [4]. HZ incidence can be high after transplantation. Kim et al. reported that HZ incidence after liver transplantation in adults was 16.3 per 1000 person-years. HZ incidence was 9.1, 10.0, and $11.9 \%$ at 3,5 , and 10 years after transplantation, respectively [5]. Postherpetic neuralgia is a painful complication; Salvetti et al. found that one-tenth of $\mathrm{HZ}$ patients suffered from this, with the highest proportion of $15.56 \%$ being found in patients aged 75-79 years [6].

Diseases with chronic pain such as adhesive capsulitis of the shoulder [7], chronic interstitial cystitis [8], and lateral epicondylitis [9] are associated with $\mathrm{HZ}$ occurrence. Sciatica is one of the diseases with chronic pain, the association between sciatica and $\mathrm{HZ}$ development might be existed. In this paper, we evaluated HZ occurrence in patients with sciatica to understand whether sciatica is a stressor leading to $\mathrm{HZ}$ development.

(C) The Author(s). 2020 Open Access This article is licensed under a Creative Commons Attribution 4.0 International License, which permits use, sharing, adaptation, distribution and reproduction in any medium or format, as long as you give appropriate credit to the original author(s) and the source, provide a link to the Creative Commons licence, and indicate if changes were made. The images or other third party material in this article are included in the article's Creative Commons licence, unless indicated otherwise in a credit line to the material. If material is not included in the article's Creative Commons licence and your intended use is not permitted by statutory regulation or exceeds the permitted use, you will need to obtain permission directly from the copyright holder. To view a copy of this licence, visit http://creativecommons.org/licenses/by/4.0/. The Creative Commons Public Domain Dedication waiver (http://creativecommons.org/publicdomain/zero/1.0/) applies to the data made available in this article, unless otherwise stated in a credit line to the data. 


\section{Methods}

\section{Study design and research database}

We designed a population-based retrospective cohort study. Here, the study data were extracted from the claims data in the Longitudinal Health Insurance Database 2000 (LHID2000); which includes systemically collected claims data of 1 million National Health Insurance (NHI) as well as the random samples in Taiwan NHI Research Database (NHIRD). NHIRD, managed by the National Health Research Institutes, contains data of beneficiaries of the NHI program established in 1995 to provide comprehensive and universal health care coverage to approximately 99\% Taiwan residents. NHIRD include data on enrollment files, claims data, disease diagnose, prescriptions, outpatient visits, and hospital admissions. All diagnoses are coded using International Classification of Diseases, Ninth Revision, Clinical Modification (ICD-9-CM) diagnostic codes. To ensure data privacy, patient data are released to researchers in an electronically encrypted form and thus, the requirement to obtain informed consent was waived. This study has been approved by the Research Ethics Committee at China Medical University Hospital (CMUH104-REC2115-CR-4).

\section{Data availability statement}

The dataset used in this study is held by the Taiwan Ministry of Health and Welfare (MOHW). The MOHW must approve our application to access this data. Any researcher interested in accessing this dataset can submit an application form to the Ministry of Health and Welfare requesting access. Please contact the staff of MOHW (Email: stcarolwu@mohw.gov.tw) for further assistance. Taiwan Ministry of Health and Welfare Address: No.488, Sec. 6, Zhongxiao E. Rd., Nangang Dist., Taipei City 115, Taiwan (R.O.C.). Phone: + 886-2-8590-6848. All relevant data are within the paper.

\section{Study population}

We identified patients first diagnosed as having sciatica (ICD-9-CM 724.3) between January 1, 2000 and December 31, 2012, and included them in the sciatica cohort. The index date was defined as the date of sciatica diagnosis. We excluded patients aged < 20 years, and with a HZ history before the index date. Every patient with sciatica was randomly age (every 5-year interval), sex and index date matched with a control individual without sciatica from the same database and then this individual was assigned to the control cohort under the same criteria.

\section{Outcome and covariate assessment}

The outcome of interest was a new diagnosis of $\mathrm{HZ}$ (ICD-9-CM 053) between January 1, 2000 and December 31, 2013. All individuals were followed until $\mathrm{HZ}$ occurrence, withdrawal from NHI, death, or December 31, 2013, whichever occurred first. We considered several covariates as potential confounders including sex, age, and baseline comorbidities. Inpatient and outpatient data were used to define the status of comorbidities including chronic kidney disease (ICD-9-CM 585and 586), obesity (ICD-9-CM 278), diabetes (ICD-9-CM 250), coronary artery disease (ICD-9CM 410-414), depression (ICD-9-CM 296.2, 296.3, 300.4 and 311), and lumbar disc herniation (ICD-9-CM 722.10).

\section{Statistical analysis}

Characteristics of all included individuals were first analyzed descriptively. The differences of categorical and continuous variables between the sciatica and control cohorts were tested using the $t$ and chi-square tests. The incidence rate was defined as the number of events per 1000 person-years. Cox proportional hazards regression model adjusted for age, sex and comorbidity was used to determine the association between sciatica and HZ risk. The results were presented as a hazard ratio (HR) with accompanying 95\% confidence interval (CI). We estimated the cumulative incidence of $\mathrm{HZ}$ in the sciatica and control cohorts by using the Kaplan-Meier method, and the differences were examined using the log-rank test. HZ risk in the two cohorts was further analyzed after age, sex and comorbidity stratification. A two-sided $p$ of $<0.05$ was considered statistically significant. All data processing and statistical analyses were performed using SAS (version 9.4; SAS Institute Inc., Cary, NC, USA).

\section{Results}

In total, 49,023 patients with sciatica and 49,023 matched controls were included. Table 1 presents the demographic characteristics and comorbidities in the two cohorts. The age and sex distribution was similar between the sciatica and control cohorts after matching. Compared with the control cohort, the sciatica cohort had significantly higher diabetes, coronary artery disease, depression, obesity, cancer and lumbar disc herniation prevalence $(p<0.001)$. The mean follow-up duration was $7.44( \pm 3.82)$ and $7.42( \pm 3.83)$ years in sciatica and control cohorts, respectively.

Cox proportional hazards regression models for analyzing the risk of variables contributing to $\mathrm{HZ}$ are presented in Table 2. After adjustment for all the covariates, the sciatica cohort had a significantly higher $\mathrm{HZ}$ risk than did the control cohort (adjusted $\mathrm{HR}=1.19$; $95 \% \mathrm{CI}=1.12-1.25)$. Moreover, HZ risk was significantly higher in patients aged 50-64 years (adjusted HR = 2.10; $95 \% \mathrm{CI}=1.97-2.23$ ) and those aged $>65$ years (adjusted $\mathrm{HR}=2.48 ; 95 \% \mathrm{CI}=2.32-2.66)$ than in those aged $<49$ years. Female patients were more likely to have $\mathrm{HZ}$ than were male patients (adjusted $\mathrm{HR}=1.07,95 \% \mathrm{CI}=1.02-$ 
Table 1 Demographic characteristics and comorbidities in cohorts with and without Sciatica

\begin{tabular}{llll}
\hline Variable & \multicolumn{2}{l}{ Sciatica } & p-value \\
\cline { 2 - 3 } & No & Yes & \\
& $\boldsymbol{N}=\mathbf{4 9 , 0 2 3}$ & $\boldsymbol{N}=\mathbf{4 9 , 0 2 3}$ & \\
\hline Age, year & & & 0.99 \\
$\quad \leq 49$ & $18,729(38.2)$ & $18,729(38.2)$ & \\
$50-64$ & $16,682(34.0)$ & $16,682(34.0)$ & \\
65+ & $13,612(27.8)$ & $13,612(27.8)$ & \\
Mean \pm SD & \\
Sex & $54.1 \pm 15.4$ & $54.8 \pm 15.1$ & $<0.001$ \\
Female & & & 0.99 \\
Male & $27,378(55.9)$ & $27,378(55.9)$ & \\
Comorbidity & $21,645(44.2)$ & $21,645(45.2)$ & \\
Diabetes & & & \\
CAD & $3849(7.85)$ & $4592(9.37)$ & $<0.001$ \\
Depression & $7491(15.3)$ & $11,260(23.0)$ & $<0.001$ \\
Chronic kidney disease & $859(1.75)$ & $926(1.89)$ & 0.11 \\
Obesity & $544(1.11)$ & $932(1.90)$ & $<0.001$ \\
Cancer & $1376(2.81)$ & $1178(2.40)$ & $<0.001$ \\
Lumbar disc herniation & $16,769(34.2)$ & $38,692(78.9)$ & $<0.001$ \\
\hline
\end{tabular}

Chi-Square Test; ${ }^{\text {a: }}$ T-Test

$C A D$ denotes coronary artery disease

1.12). Moreover, patients with diabetes, coronary artery disease, depression, chronic kidney disease, cancer and lumbar disc herniation had a significantly higher $\mathrm{HZ}$ risk than did those without any comorbidity.

Table 3 presents the stratification analysis results. After age, sex and comorbidity stratification, HZ incidence was significantly higher in the sciatica cohort than in the control cohort $(p<0.001)$. Similarly, the KaplanMeier analysis results revealed that the cumulative incidence of $\mathrm{HZ}$ was significantly different between the sciatica and control cohorts (log-rank test, $p<0.001$; Fig. 1).

Similar results were observed for HZ by propensity score methods as sensitivity analysis. We recreated a non-sciatica cohort well matched for age, sex, index year and comorbidities including diabetes, CAD, depression, chronic kidney disease, obesity, cancer, lumbar disc herniation (Table 4). With this newly selected non-sciatica cohort, the associations between sciatica and HZ (adjusted $\mathrm{HR}=1.19,95 \% \mathrm{CI}=1.12-1.27$ ) remained strongly (Table 5).

\section{Discussion}

This is the first population-based study to assess $\mathrm{HZ}$ risk in patients with sciatica; patients with sciatica were 1.19 times more likely to develop HZ than were those without.
About $90 \%$ of sciatica is caused by spinal disc herniation [10]. Because an inflammatory response in the lumbosacral nerve roots due to herniated nucleus pulposus and mechanical deformation on the nerve, sensation of pain occurs [11]. However, Stafford et al. emphasized that herniation of nucleus pulposus is not the only cause of sciatica, and we should not forget other causes [11].

Diseases with chronic pain such as adhesive capsulitis of the shoulder [7], chronic interstitial cystitis [8], and lateral epicondylitis [9] are associated with risk of HZ. Sciatica is one of common chronic pain syndrome which is a stressor for affected individual. Stress can activate neural or hormonal activity in order to restore homeostasis [12]. It is believed that stress and pain will produce changes in the perceptual and stress system, resulting in abnormal output patterns of the body's own neuromatrix [12]. These mechanisms are strongly associated with decreasing the VZV-specific cellular immunity; thus, increasing risk of $\mathrm{HZ}$ in patients with sciatica should be considered.

In a comprehensive review of the evidence from systematic reviews, Parreira et al. identified risk factors for sciatica from 54 items, with depression being an adverse risk factor [13]. Oosterhuis et al. investigated prognostic factors for work participation in patients with sciatica through systemic reviews and found a similar result: less depression was a favourable factor for return to work [14]. Lower back pain is a discomfort experienced by patients with sciatica. Tutoglu et al. assessed depression severity in patients with sciatica and neuropathic pain, sciatica without neuropathic pain, and healthy participants by using Beck Depression Inventory (BDI) and found mean BDI scores of $5.89( \pm 5.37), 20.88( \pm 12.39)$ and $4.21( \pm 5.95)$. BDI was significantly higher in patients with sciatica and neuropathic pain [15]. Max et al. examined depression symptoms by using the 36 -items short form of Mental Health Scale for patients with sciatica after surgery and found that depression symptoms were significantly alleviated after surgery if the pain was reduced by $>25 \%$. And, the mean score remained unchanged if there was no or only slight pain relief [16]. The patients with chronic pain may experience depression [17]. Narita et al. reported that chronic pain had an anxiogenic effect in mice and that this phenomenon may be associated with changes in opioidergic function in the amygdala [17]. The mechanisms of pain leading to depression were identified by Max et al. through pain-gene interaction by using a clinical genetic method, they considered that the short-term and 1-year effect on mood after surgery for sciatica was on the mu opioid receptor and galanin-2 receptor [16].

Irwin et al. found that depression is associated with decreasing VZV-specific cellular immunity [18]. Thus, the risk of $\mathrm{HZ}$ is increased in patients with depression. 
Table 2 The incidence and risk factors for herpes zoster

\begin{tabular}{|c|c|c|c|c|c|}
\hline Variable & Event & PY & Rate $^{a}$ & Crude HR(95\% Cl) & $\begin{array}{l}\text { Adjusted } \mathrm{HR}^{\mathrm{b}} \\
(95 \% \mathrm{Cl})\end{array}$ \\
\hline \multicolumn{6}{|l|}{ Sciatica } \\
\hline No & 2899 & 368,778 & 7.86 & 1.00 & 1.00 \\
\hline Yes & 3981 & 375,977 & 10.6 & $1.35(1.28,1.41)^{* * *}$ & $1.19(1.12,1.25)^{* * *}$ \\
\hline \multicolumn{6}{|l|}{ Age, year } \\
\hline$\leq 49$ & 1551 & 310,651 & 4.99 & 1.00 & 1.00 \\
\hline $50-64$ & 2839 & 254,722 & 11.2 & $2.25(2.11,2.39)^{* * *}$ & $2.10(1.97,2.23)^{* * *}$ \\
\hline $65+$ & 2490 & 179,382 & 13.9 & $2.84(2.67,3.03)^{* * *}$ & $2.48(2.32,2.66)^{* * *}$ \\
\hline \multicolumn{6}{|l|}{ Sex } \\
\hline Female & 4192 & 426,137 & 9.84 & $1.16(1.11,1.22)^{* * *}$ & $1.07(1.02,1.12)^{*}$ \\
\hline Male & 2688 & 318,618 & 8.44 & 1.00 & 1.00 \\
\hline \multicolumn{6}{|c|}{ Comorbidity } \\
\hline \multicolumn{6}{|c|}{ Diabetes } \\
\hline No & 6113 & 690,290 & 8.86 & 1.00 & 1.00 \\
\hline Yes & 767 & 54,465 & 14.1 & $1.61(1.50,1.74)^{* * *}$ & $1.14(1.05,1.12)^{* *}$ \\
\hline \multicolumn{6}{|l|}{ CAD } \\
\hline No & 5039 & 615,072 & 8.19 & 1.00 & 1.00 \\
\hline Yes & 1841 & 129,683 & 14.2 & $1.75(1.66,1.85)^{* * *}$ & $1.18(1.12,1.25)^{* * *}$ \\
\hline \multicolumn{6}{|c|}{ Depression } \\
\hline No & 6455 & 709,775 & 9.09 & 1.00 & 1.00 \\
\hline Yes & 425 & 34,980 & 12.2 & $1.36(1.23,1.50)^{* * *}$ & $1.11(1.01,1.23)^{*}$ \\
\hline \multicolumn{6}{|c|}{ Chronic kidney disease } \\
\hline No & 6727 & 735,561 & 9.15 & 1.00 & 1.00 \\
\hline Yes & 153 & 9193 & 16.6 & $1.88(1.60,2.20)^{* * *}$ & $1.28(1.09,1.50)^{* *}$ \\
\hline \multicolumn{6}{|l|}{ Obesity } \\
\hline No & 6788 & 735,209 & 9.23 & 1.00 & 1.00 \\
\hline Yes & 92 & 9546 & 9.64 & $1.06(0.87,1.31)$ & \\
\hline \multicolumn{6}{|l|}{ Cancer } \\
\hline No & 6691 & 730,816 & 9.16 & 1.00 & 1.00 \\
\hline Yes & 189 & 13,939 & 13.6 & $1.51(1.31,1.75)^{* * *}$ & $1.21(1.05,1.40)^{*}$ \\
\hline \multicolumn{6}{|c|}{ Lumbar disc herniation } \\
\hline No & 2538 & 348,796 & 7.28 & 1.00 & 1.00 \\
\hline Yes & 4342 & 395,959 & 11.0 & $1.53(1.46,1.61)^{* * *}$ & $1.24(1.17,1.31)^{* * *}$ \\
\hline
\end{tabular}

Rate $^{\mathrm{a}}$, incidence rate, per 1000 person-years; Crude HR, relative hazard ratio; Adjusted $\mathrm{HR}^{\mathrm{b}}$ : multivariable analysis including age, sex, and comorbidities of diabetes, and CAD;

${ }^{*} p<0.05,{ }^{* *} p<0.01,{ }^{* * *} p<0.001$

Choi et al. found that $\mathrm{HZ}$ prevalence was $6.8 \%$ in patients with depression and $6.3 \%$ in controls and that patients with depression had a 1.09 times higher HZ risk than did those without depression [19]. In a similar populationbased study of Liao et al., HZ incidence was 4.58 and 3.54 per 1000 person-years in patients with depression and controls. In addition, their case cohort was 1.11 times more likely to develop $\mathrm{HZ}$ than was their control cohort [20]. Because sciatica and sciatica-related conditions such as pain and depression are stressful, there is a strong possibility for sciatica patients to develop HZ.

$\mathrm{HZ}$ prevalence typically increases with age as corroborated by our results (Table 1); among our patients with sciatica, HZ incidence was higher in patients aged $<65$ years (Table 3). Furthermore, regardless of whether the patients had comorbilities, HZ incidence remained high. These results confirmed that the presence of sciatica might be a stressor leading to $\mathrm{HZ}$ development. 
Table 3 Incidence of herpes zoster by age, sex and comorbidity and Cox model measured hazards ratio for patients with Sciatica compared those without Sciatica

\begin{tabular}{|c|c|c|c|c|c|c|c|c|}
\hline \multirow[t]{3}{*}{ Variables } & \multicolumn{6}{|c|}{ Sciatica } & \multirow{3}{*}{$\begin{array}{l}\text { Crude HR } \\
(95 \% \mathrm{Cl})\end{array}$} & \multirow{3}{*}{$\begin{array}{l}\text { Adjusted HR } \\
(95 \% \mathrm{Cl})\end{array}$} \\
\hline & \multicolumn{3}{|l|}{ No } & \multicolumn{3}{|l|}{ Yes } & & \\
\hline & Event & PY & Rate $^{\mathrm{a}}$ & Event & PY & Rate $^{a}$ & & \\
\hline \multicolumn{9}{|l|}{ Age, years } \\
\hline$\leq 49$ & 662 & 154,980 & 4.27 & 889 & 155,671 & 5.71 & $1.34(1.21,1.48)^{* * *}$ & $1.17(1.04,1.31)^{* * *}$ \\
\hline $50-64$ & 1174 & 127,099 & 9.24 & 1665 & 127,623 & 13.1 & $1.41(1.31,1.52)^{* * *}$ & $1.30(1.19,1.41)^{* * *}$ \\
\hline $65+$ & 1063 & 86,700 & 12.3 & 1427 & 92,682 & 15.4 & $1.25(1.16,1.36)^{* * *}$ & $1.11(1.02,1.21)^{* * *}$ \\
\hline \multicolumn{9}{|l|}{ Sex } \\
\hline Female & 1758 & 211,353 & 8.32 & 2434 & 214,784 & 11.3 & $1.36(1.28,1.45)^{* * *}$ & $1.21(1.14,1.30)^{* * *}$ \\
\hline Male & 1141 & 157,426 & 7.25 & 1547 & 161,192 & 9.60 & $1.32(1.23,1.43)^{* * *}$ & $1.14(1.04,1.24)^{* * *}$ \\
\hline \multicolumn{9}{|c|}{ Comorbidity $^{c}$} \\
\hline No & 1242 & 213,614 & 5.81 & 586 & 73,197 & 8.01 & $1.35(1.22,1.49)^{* * *}$ & $1.37(1.24,1.51)^{* * *}$ \\
\hline Yes & 1657 & 155,164 & 10.7 & 3395 & 302,780 & 11.2 & $1.04(0.98,1.11)$ & $1.14(1.08,1.21)^{* * *}$ \\
\hline
\end{tabular}

Rate $^{\mathrm{a}}$, incidence rate, per 1000 person-years; Crude HR, relative hazard ratio; Adjusted $\mathrm{HR}^{\mathrm{b}}$ : multivariable analysis including age, sex, and comorbidities of diabetes, $C A D$, and lumbar disc herniation;

'Individuals with any comorbidity of diabetes, CAD, depression, and chronic kidney disease, obesity, cancer, and lumbar disc herniation were classified into the comorbidity group

${ }^{* * *} p<0.001$

\section{Limitations}

This was a retrospective study and thus there were several limitations. First, sciatica severity and HZ severity and location which may affect the treatment decision and prognosis, are unavailable in NHIRD. Second, lifestyles information such as smoking, is also unavailable in the NHIRD. A strongly association between smoking and sciatica was confirmed by several studies [13, 21]. This could also influence the outcome of this study. Third, influence of medication was not analyzed in the

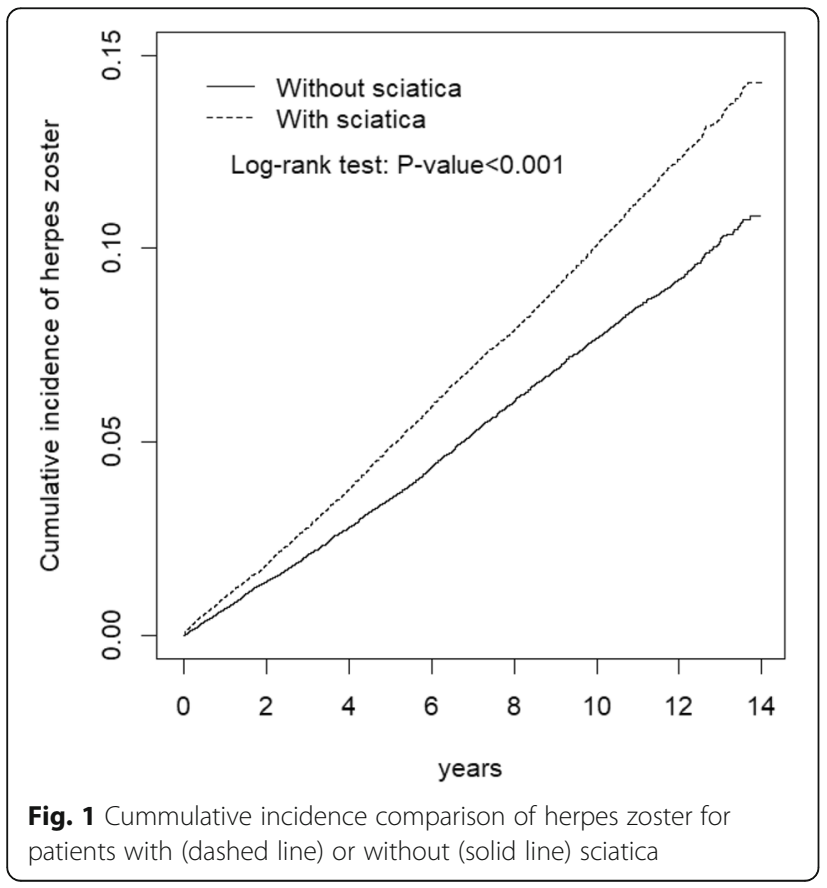

present study. Drugs may influence the immune system which resulted to $\mathrm{HZ}$ occurrence. However, medication will be given immediately after diagnosis of diseases in both groups due to the unique insurance system with high accessibility, thus the medication bias can be

Table 4 Demographic characteristics and comorbidities in cohorts with and without sciatica by propensity score matching

\begin{tabular}{|c|c|c|c|}
\hline \multirow[t]{3}{*}{ Variable } & \multicolumn{2}{|l|}{ Sciatica } & \multirow[t]{3}{*}{$p$-value } \\
\hline & No & Yes & \\
\hline & $N=27,097$ & $N=27,097$ & \\
\hline Age, year & & & 0.74 \\
\hline$\leq 49$ & $9228(34.1)$ & $9262(34.2)$ & \\
\hline $50-64$ & $9400(34.7)$ & 9378 (34.6) & \\
\hline $65+$ & 8469 (31.3) & $8457(31.2)$ & \\
\hline Mean $\pm S D^{a}$ & $55.8 \pm 15.1$ & $55.8 \pm 15.2$ & 0.99 \\
\hline Sex & & & 0.99 \\
\hline Female & $15,740(58.1)$ & $15,778(58.2)$ & \\
\hline Male & $11,357(41.9)$ & $11,319(41.8)$ & \\
\hline \multicolumn{4}{|l|}{ Comorbidity } \\
\hline Diabetes & $2488(9.18)$ & $2488(9.03)$ & 0.55 \\
\hline CAD & $5517(20.4)$ & $5528(20.4)$ & 0.91 \\
\hline Depression & $1438(5.31)$ & $1457(5.38)$ & 0.72 \\
\hline Chronic kidney disease & $508(1.87)$ & $458(1.69)$ & 0.10 \\
\hline Obesity & $384(1.42)$ & $379(1.40)$ & 0.86 \\
\hline Cancer & $772(2.85)$ & $719(2.65)$ & 0.16 \\
\hline Lumbar disc herniation & 16,769 (61.9) & $16,766(61.9)$ & 0.98 \\
\hline
\end{tabular}

Chi-Square Test; ${ }^{\text {a: }}$ T-Test

$C A D$ denotes coronary artery disease 
Table 5 Overall Incidence of herpes zoster (per 1000 personyears) and estimated hazard ratios according to sciatica status using Cox method by propensity score matching

\begin{tabular}{|c|c|c|}
\hline & \multicolumn{2}{|l|}{ Sciatica } \\
\hline & No & Yes \\
\hline Variable & $(N=27,097)$ & $(N=27,097)$ \\
\hline \multicolumn{3}{|l|}{ Herpes zoster. } \\
\hline Person-years & 203,946 & 208,742 \\
\hline Follow-up time $(y)$, Mean $\pm S D$ & $7.53 \pm 3.87$ & $7.70 \pm 3.84$ \\
\hline Event, $\mathrm{n}$ & 1813 & 2239 \\
\hline Rate $^{a}$ & 8.89 & 10.7 \\
\hline Crude HR (95\% Cl) & 1 (Reference) & $1.21(1.13,1.28)^{* * *}$ \\
\hline Adjusted HR $(95 \% \mathrm{Cl})$ & 1(Reference) & $1.19(1.12,1.27)^{* * *}$ \\
\hline
\end{tabular}

Rate ${ }^{\mathrm{a}}$, incidence rate, per 1000 person-years; Crude HR, relative hazard ratio; Adjusted $\mathrm{HR}^{\mathrm{b}}$ : multivariable analysis including age, sex, and comorbidities of diabetes, and $C A D$

*** $p<0.001$

ignored. Fourth, diagnostic bias between different specialists may occur. Nevertheless, all insurance claims are sent to the NHI Administration and reviewed by experts through a strict system of audit and penalty. Therefore, the diagnostic codes are reliable. Despite these limitations, the population-based study provided sufficient evidence for persuasive research through inclusion a large number of patients. Thus, we confirm that $\mathrm{HZ}$ risk is higher in patients with sciatica than in those without.

\section{Conclusion}

The presence of sciatica increased HZ risk. Thus, HZ risk should be noted when physicians encounters patients with sciatica, and $\mathrm{HZ}$ vaccination should be considered especially those aged over 50 .

\section{Abbreviations}

HZ: Herpes zoster; HR: Hazard ratio; Cl: Confidence interval; VZV: Varicellazoster virus; LHID2000: Longitudinal Health Insurance Database 2000; NHIR D: National Health Insurance Research Database; ICD-9-CM: International Classification of Diseases, Ninth Revision, Clinical Modification; BDI: Beck Depression Inventory

\section{Acknowledgements}

Not Applicable.

\section{Authors' contributions}

KDS and HCY was responsible for design, conceptualization; $\mathrm{KCH}$ was provision of study materials; LCL made the statistical data analysis; KDS, HCY, $\mathrm{LCL}, \mathrm{HCY}$ and $\mathrm{KCH}$ contributed collection and/or assembly of data, manuscript writing and final approval of manuscript.

\section{Funding}

This study is supported in part by Taiwan Ministry of Health and Welfare Clinical Trial Center (MOHW109-TDU-B-212-114004), China Medical University Hospital (CMU107-ASIA-19, DMR-109-231); MOST Clinical Trial Consortium for Stroke (MOST 108-2321-B-039-003-), Tseng-Lien Lin Foundation, Taichung, Taiwan. The funders had no role in the study design, data collection and analysis, the decision to publish, or preparation of the manuscript. No additional external funding was received for this study.

\section{Availability of data and materials}

The dataset used in this study is held by the Taiwan Ministry of Health and Welfare (MOHW). The Ministry of Health and Welfare must approve our application to access this data. Any researcher interested in accessing this dataset can submit an application form to the Ministry of Health and Welfare requesting access. Please contact the staff of MOHW (Email:

stcarolwu@mohw.gov.tw) for further assistance. Taiwan Ministry of Health and Welfare Address: No.488, Sec. 6, Zhongxiao E. Rd., Nangang Dist., Taipei City 115, Taiwan (R.O.C.). Phone: $+886-2-8590-6848$. All relevant data are within the paper.

\section{Ethics approval and consent to participate}

The NHIRD encrypts patient personal information to protect privacy and provides researchers with anonymous identification numbers associated with relevant claims information, including sex, date of birth, medical services received, and prescriptions. Therefore, patient consent is not required to access the NHIRD. This study was approved to fulfill the condition for exemption by the Institutional Review Board (IRB) of China Medical University (CMUH104-REC2-115-AR4). The IRB also specifically waived the consent requirement.

\section{Consent for publication}

Not applicable.

\section{Competing interests}

The authors declare no financial or other conflicts of interest.

\section{Author details}

${ }^{1}$ Department of Medical Education, Ditmanson Medical Foundation Chia-Yi Christian Hospital, Chia-Yi, Taiwan. ${ }^{2}$ Department of Optometry, Central Taiwan University of Science and Technology, Taichung, Taiwan. ${ }^{3}$ Center for General Education, National Taichung University of Science and Technology, Taichung, Taiwan. ${ }^{4}$ Department of General Education, National Chin-Yi University of Technology, Taichung, Taiwan. ${ }^{5}$ The General Education Center, Chaoyang University of Technology, Taichung, Taiwan. ${ }^{6}$ Center for General Education, National Chi Nan University, Puli, Taiwan. ${ }^{7}$ Rural Generalist Program Japan, GENEPRO, Chiba, Japan. ${ }^{8}$ Management Office for Health Data, China Medical University Hospital, Taichung, Taiwan. ${ }^{9}$ College of Medicine, China Medical University, Taichung, Taiwan. ${ }^{10}$ Graduate Institute of Biomedical Sciences and School of Medicine, College of Medicine, China Medical University, No. 2, Yuh-Der Road, Taichung 404, Taiwan. ${ }^{11}$ Department of Nuclear Medicine and PET Center, China Medical University Hospital, Taichung, Taiwan. ${ }^{12}$ Department of Bioinformatics and Medical Engineering, Asia University, Taichung, Taiwan. ${ }^{13}$ Center of Augmented Intelligence in Healthcare, China Medical University Hospital, Taichung, Taiwan.

Received: 1 June 2020 Accepted: 30 November 2020

Published online: 05 December 2020

\section{References}

1. Konstantinou K, Dunn KM. Sciatica: review of epidemiological studies and prevalence estimates. Spine (Phila Pa 1976). 2008;33(22):2464-72.

2. Cook CE, Taylor J, Wright A, Milosavljevic S, Goode A, Whitford M. Risk factors for first time incidence sciatica: a systematic review. Physiother Res Int. 2014;19(2):65-78

3. Jensen RK, Kongsted A, Kjaer P, Koes B. Diagnosis and treatment of sciatica. BMJ. 2019;367:16273.

4. Tseng HF, Bruxvoort $K$, Ackerson B, Luo Y, Tanenbaum H, Tian Y, et al. The epidemiology of herpes zoster in immunocompetent, unvaccinated adults $\geq 50$ years old: incidence, complications, hospitalization, mortality, and recurrence. J Infect Dis. 2020;222(5):798-806.

5. Kim W, Kim S, Oh J, Jeong YJ, Rhu J, Kim KS, et al. Incidence and risk factors for herpes zoster after adult liver transplantation. Ann Surg Treat Res. 2019; 96(2):95-9.

6. Salvetti A, Ferrari V, Garofalo R, Gazzaniga P, Guerroni A, Metrucci A, et al. Incidence of herpes zoster and postherpetic neuralgia in Italian adults aged $\geq 50$ years: a prospective study. Prev Med Rep. 2019:14:100882.

7. Hsu CY, Ke DS, Lin CL, Kao CH. Risk of herpes zoster in patients with adhesive capsulitis of the shoulder. Int J Environ Res Public Health. 2020; 17(10):E3592. 
8. Hsu CY, Lin CL, Kao CH. Association between chronic interstitial cystitis and herpes zoster. Int J Environ Res Public Health. 2020;17(7):E2228.

9. Hsu CY, Ke DS, Lin CL, Kao CH. Association between lateral epicondylitis and the risk of herpes zoster development. Postgrad Med. 2020. https://doi.org/ 10.1080/00325481.2020.1816713 Online ahead of print.

10. Valat JP, Genevay S, Marty M, Rozenberg S, Koes B. Sciatica. Best Pract Res Clin Rheumatol. 2010;24(2):241-52.

11. Stafford MA, Peng P, Hill DA. Sciatica: a review of history, epidemiology, pathogenesis, and the role of epidural steroid injection in management. $\mathrm{Br}$ J Anaesth. 2007;99(4):461-73.

12. Livengood JM. The role of stress in the development of herpes zoster and postherpetic neuralgia. Curr Rev Pain. 2000;4(1):7-11.

13. Parreira P, Maher CG, Steffens D, Hancock MJ, Ferreira ML. Risk factors for low back pain and sciatica: an umbrella review. Spine J. 2018;18(9):1715-21.

14. Oosterhuis T, Smaardijk VR, Kuijer PPF, Langendam MW, Frings-Dresen MHW, Hoving JL. Systematic review of prognostic factors for work participation in patients with sciatica. Occup Environ Med. 2019; 76(10):772-9

15. Tutoglu A, Boyaci A, Karababa IF, Koca I, Kaya E, Kucuk A, et al. Psychological defensive profile of sciatica patients with neuropathic pain and its relationship to quality of life. Z Rheumatol. 2015;74(7):646-551.

16. Max MB, Wu T, Atlas SJ, Edwards RR, Haythornthwaite JA, Bollettino AF, et al. A clinical genetic method to identify mechanisms by which pain causes depression and anxiety. Mol Pain. 2006;2:14.

17. Narita M, Kaneko C, Miyoshi K, Nagumo Y, Kuzumaki N, Nakajima M, et al. Chronic pain induces anxiety with concomitant changes in opioidergic function in the amygdala. Neuropsychopharmacology. 2006;31(4):739-50.

18. Irwin M, Costlow C, Williams H, Artin KH, Chan CY, Stinson DL, et al. Cellular immunity to varicella-zoster virus in patients with major depression. J Infect Dis. 1998;178(Suppl 1):S104-8.

19. Choi HG, Kim EJ, Lee YK, Kim M. The risk of herpes zoster virus infection in patients with depression: a longitudinal follow-up study using a national sample cohort. Medicine (Baltimore). 2019;98(40):e17430.

20. Liao CH, Chang CS, Muo CH, Kao CH. High prevalence of herpes zoster in patients with depression. J Clin Psychiatry. 2015;76(9):e1099-104.

21. Shiri R, Euro U, Heliövaara M, Hirvensalo M, Husgafvel-Pursiainen $K$, Karppinen J, et al. Lifestyle risk factors increase the risk of hospitalization for sciatica: findings of four prospective cohort studies. Am J Med. 2017;130(12): 1408-1414.e6.

\section{Publisher's Note}

Springer Nature remains neutral with regard to jurisdictional claims in published maps and institutional affiliations.

Ready to submit your research? Choose BMC and benefit from:

- fast, convenient online submission

- thorough peer review by experienced researchers in your field

- rapid publication on acceptance

- support for research data, including large and complex data types

- gold Open Access which fosters wider collaboration and increased citations

- maximum visibility for your research: over $100 \mathrm{M}$ website views per year

At $\mathrm{BMC}$, research is always in progress.

Learn more biomedcentral.com/submissions 